\title{
Power and Culture in Human-Centric Innovation Ecosystems
}

\author{
Keisha LaRaine Ingram \\ Corresponding author: klingram@mruni.eu \\ Mykolas Romeris University \\ Lithuania
}

\section{About the author}

Keisha LaRaine Ingram obtained her undergraduate Structural Engineering Diploma and Construction Engineering from the University of Technology, Jamaica. She completed two master degrees in Electronic Business Management and Social Technologies Management at Mykolas Romeris University, Lithuania. Currently she is pursuing doctoral research studies in Lithuania and is scheduled to complete her joint Ph.D. program in Management in 2020. She has the internship experience in international organizations and institutions, such as Johannes Kepler University, in Austria in 2014 and the United Nations Development Fund (UNDP) in 2015. Her research expertise includes Structural Engineering, Civil Engineering, Electronics and Electrical Engineering, Business Management and Innovation.

\section{Abstract}

This paper reviews and analyses the role of power and culture management theories on the implementation of human-centric innovation ecosystems in organizations and corporations from an institutional aspect. The practical aspects and characteristics of management theories paradigms are discussed, for highlighting the development of specific-based strategies that an organization adapts in order to harness the right kind of talent or human capital to foster and support innovation ecosystems. The relevant literature findings are organized in three sections, namely the evolution of management theories paradigms leading to the development of innovation management theory, the role of organizational power and culture in the fostering an innovation-based system and environment internally, and to a greater extent, the impact of this power and culture on the development of human-centric innovation ecosystems. The findings reveal that rather than focusing on the technological and financial aspects of innovation ecosystems, power and culture within the organizational context essentially contributes to the extent to which innovation is properly supported and implemented, the changing dynamics involved and actors in those ecosystems. It is, therefore, important to choose the culture of the entrepreneurial model methodology, best practices and techniques and approaches in order to influence ecosystems found in organizations within the domain of management theory.

Keywords:Culture; Power; Innovation ecosystems; Innovation; Human capital 


\section{Introduction}

Management theories are more or less paradigms constructed to provide solutions to identified managerial problems, which span from the nineteenth to the twentieth century. In a chronological order, these paradigms have been termed historically as 'Scientific Management', 'Human Relations' and 'Structural Revolution', with the evolution of each emanating into practical applicability in organizations. The paradigms of management theories are strongly rooted from the main idea that management principles and systems are increasingly becoming inadequate in fully addressing the evolving nature of contemporary internal organizational culture and power systems, and externally the rapid development and prevalence of business and innovation ecosystems and industrial clusters. Intrinsically, organizational culture and power has evolved to become an essential element in understanding the way things are done in organizations and its governance. There is a strong correlation between organizational culture and power in that it is at the heart of every organization and an indisputable part of everyday life affecting all aspects of social relationships. Organizational culture gained interest during the 1970s and 1980s after the decline in the development of motivation models that led to culture evolving into the 'new paradigm' set to secure and retain employees to organizations. The nature

of power and politics are to greater extent shaped by organizational culture, how persons view themselves or situated within a particular discourse of power, which gives rise to differential power relations.

In regards to innovation, it has become omnipresent especially in today's technologically driven world (Godin, 2008). According to Godin (2008), innovation is one of the most highly 'discussed phenomena', and in recent times in all sphere of scientific and technical literature, social sciences, humanities, arts and technology (practical and theoretical applications). In a nutshell, not only has innovation evolved to become the emblem of modern society, it has become the cure-all for resolving many problems, a deep fascination, intellectual or practical quest and a dynamic phenomenon that needs to be studied (Nowotny 2008; 2006, Godin, 2008). Innovation is very important for developed economies (Kuhlmann, 2001; Simonen and McCann, 2008), as it is termed as cognitive enhancement 'technology' for improving humanity innovative abilities (Greely et al., 2008), and the 'engine of growth' or 'creative destruction' (Schumpeter, 1934). Then there is the 'human capital' a term used by economists and social scientists to refer to the knowledge, skills, and capabilities embodied in people involved in the innovation process (Abel and Gabe, 2011). Blaug (1976) has countered that the qualities encompassed by the workforce in a company, organization or the population of a country should not be reduced to a single theory, that is human capital. It was not until the late 1950s to the early 1960 s, did the concept of human capital started feature strongly in the economic literature as an essential part to production and worthy of examination and economic consideration. Rowley (2001), Storper and Scott (2009) contends that: "human capital is the embodiment of knowledge in terms of the understanding, practices, awareness and creation of tacit knowledge within people".

Organization and business ecosystems are a new and emerging branch of theory in the field of strategic management in that it uses concepts and terms analogous to ecology. By developing a new and innovative view on relations between organizations in regards to the interconnectedness and interdependency of each 
member, ecosystems co-evolve and share a similar fate. This where the concept of business and organization ecosystems are referenced in that regard, because organizations are consistently influenced, in a simultaneous manner by interactions inside the ecosystem as well as their internal capabilities as an independent entity. Hence, an organisation's strategies should be aligned in respect to both its internal/external environment, and its respective business ecosystem. This is crucial in order to envisage its position, the role of each actor and their respective contribution to the ecosystem, and the stage and strategies utilised that ecosystem as well.

\section{Evolution of Organizational Culture and Power}

Historically, numerous attempts to define culture have been done, with each definition describing culture according to its specific context. Brown (1998) defines culture as a concept that covers a wide range of behaviour, which pertains to the methods of production; job skills and technical knowledge; attitudes towards discipline and punishment; custom and habits of managerial behaviour; the objectives of concern; a way of doing business or the values placed on different types of work (Jacques 1952, p.251). Indeed, these terms are varying definitions of culture derived from the contextual actuality of the perceptions and meanings ascribed to culture. However, when collectively put together these terms give a general description of culture. Nonetheless, the culture of an organization refers to the unique configuration of norms, values beliefs and ways of behaving which characterize the manner in which groups and individuals combine to get things done. On the other hand, Pacanowsky and O'Donnell-Trujillo (1982) states that organizational culture is not just a piece of the puzzle in management rather it is the puzzle as culture is not something an organization has rather it is something that an organization is. As a pattern of basic assumptions, culture can be invented, discovered or developed by a given group as a way of coping with its problems with the external adaptation and internal integration. When it is successful, it is considered valid and therefore taught to new members as the correct way to perceive, think and feel in relation to these problems (Schein, 1985, p.9). For top management, culture is viewed as the shared beliefs in an organization, which dictates how top management should manage themselves and other employees as well as how to conduct business. These beliefs are invisible to top managers but have a significant impact on their thoughts and actions (Lorsch 1986, p.95). Culture is perceived as 'the way how things are done around here' (Handy, 1976) and can be typical of the organization, the habits practised, and the prevailing attitudes and mature patterns of accepted and expected behaviour (Drennan, 1992). Organizational culture is strongly related to, in many ways, a system of shared meanings and thoughts held by members that clearly distinguish the organization from other organizations, which in retrospect is difficult to articulate or explain by the members to others. Where culture is perceived 'as not what an organization has but what it is' (Smircich, 1983), culture in this context then becomes a process that happens, but is also the outcomes working in the broader society; hence the organization is both a product and a producer of culture. Organizational culture and environments most often are structured and by the actions of certain key players, where for example, strategic planners and managers strive at maintaining multiple key roles within their organizations to pursue and promote their agenda for strategic 
implementation. This ensures that a strategy, by way of corporate culture is continuously instilled according to actions of these key players. Hence, a strategy formulation or paradigm which inherently is a political process that involves various groups and individuals pursuing their own interest using power and influence, also acts as the "roadmap" for organizations in identifying specific objectives, plans and policies that will be implemented.

Using Kuhn's theory within an organizational context, a paradigm is the formula or recipe for addressing what the organization is and what is does as well as what individuals think that the organizational should be doing in order to counter these problems. This paradigm presents the resilience level of organizations to change and strategic drift. A strategic drift occurs when the organization or management thereof becomes significantly out of line or step with its environment, while believing that it is endeavouring to do everything conceivable to keep up. As such, incremental change results yet are reduced through the biased perceptions an organization has of its environment and the resulting cultural changes made will become insignificant due to its cultural filter. Hence, when a crisis approaches, the organization will abandon its incremental progress and adopts a radical change or turnaround, which becomes necessary in order to survive. Mintzberg (1978), welcomes this radical turnaround stage and is very optimistic because it is his belief that organizations have always deliberately allowed planned and emergent strategies to coexist. Furthermore, many largescale mass production organizations are characterized as applying an incrementalism in response to change and note that some organizations are designed and operate to institutionalize change and encourage both emergent and deliberate strategies. In lieu of this, Mintzberg believes that managing incremental change is predominant and normal strategic role for most managers and those 'tasked' with crafting a strategy. In applying Kuhn's theory, the phenomena of culture are a series of paradigms, historically shifting from the classic and traditional perspectives (positivist approach) then towards the modernist perspectives (interpretivist approach), and postmodernist perspectives (generally, no preference to the interpretivist or positivist approach- all compassing paradigm) (Kuhn, 1970; Marcum, 2005).

From an interpretivist perspective, social psychologists French and Raven (1959) attempted to demonstrate the origins of power in an organization, as to understand why some leaders are influential and how individuals and work teams are willing to accept their power as well. In understanding power, French and Raven states, that there are five bases of power, which are:

- Legitimate power (derived from the belief a person inherently has the formal power to make demands and expects subordination and compliance from others)

- Reward power (derived from the ability of one person to compensate another for being compliant)

- Expert power (this power is ascribed to an individual due his/or her skills and knowledge.

- Referent power - (resulting from the perceived attractiveness, merit or right to demand respect from others)

- Coercive power (derived from the belief that one can punish others for non-compliance - This comes from the belief that a person can punish others for noncompliance.

Years later, Raven (1965) added an extra power base, informational where power is largely derived from an 
individual's ability to control information that others will need to accomplish something.

Handy's typology of power defines and groups power into two main perspectives, 'power resources' (often termed as physical, resource, position, expert, negative or personal types of powers) and 'influence' (these are rules and procedures, force, exchange, persuasion, ecology or magnetism types of power). In a similar manner, this power is applicable to 'all managers' and has successfully advanced the pluralist theory that power is not an absolute factor in social relationship rather it varies according the salience or relevance of another individual, or the balance of power between individuals. As such, Handy (1985) argues that resources can be used positively accordingly, to gain promotion, support peers, achieve results, or from a negative stance, hinder or disrupt as in the case innovation. Handy further contends that managers aspire to succeed in acquiring all power resources, hence the dimension of influence to facilitate and exert his or her power on other individuals, but the choice of the method employed is highly dependent on the organization's environment and culture.

Following the interpretivist perspective, Kotter (1977) postulated four methods through which managers can acquire power in an organization. The first type is where power is created from a sense of obligation in others, or in other words, when managers are successful, others feel obligated to allow managers to influence them only to a certain degree or limit. The second type of power is based on the belief in a manager's expertise (expert power) where individuals will submit to the manager, or in other words power that is built on one's reputation and experience. Using Freud's theory on unconscious, Kotter perceives that both conscious and unconscious idealizations of a manager generate the source of power. Lastly, the fourth source of power arises from a "perceived dependence on a manager" (Kotter, 1977; p. 131) which is acquired through accrued resources or the perception of this addition.

Mintzberg (1983) have adopted a similar approach to Kotter (1977), and have presented the interpretations of one more overt form of power and influence available to managers. Using the 'political games' model Mintzberg (1983) successfully outlines the strategies used by mangers considered effective in protecting one's position, while coping with other organizational threats and uncertainties. It is argued that political games help to build power bases in organizations and tend to involve factors such as:

- Securing a powerful sponsor or 'star';

- Building an empire with subordinates (very culture inherent);

- Flaunting one's experience or authority.

Furthermore, Mintzberg (1983) contends that when played in moderation, these 'games' can be healthy, however in excess they can become destructive to an organization's survival. The issue of change as well as the identification of power resources and their deployment raises the question of how power is beneficial to organizations- would it be that empowerment within the perspective of innovation, legitimises that power is indeed integral and a vital part of management and organizations survival and governance and hence far from a negative thing. Then there is the aspect of culture, in that it is difficult to separate from power and structure (organization hierarchal structure). The framework of culture and power is a direct relationship, where power-related behaviours and cultures are highly characteristic to the different types of a culture that 
works best in each culture. However, in adapting the power concept into the culture framework, one will see how power directly influences culture in organizations. Handy concept is one that prompts scholars for many years to structure into culture and as such has identified four types of cultures, 'Power Culture', 'Role Culture', 'Task Culture' and 'Person Culture'.

Power culture is one that is analogised to a 'spider's web' and refers how its control spreads out from the web center onto the rest of the organisation (Handy, 1993). Such type of power systems are characteristically found in small entrepreneurial organisations. Usually when the organisations bureaucracy adopts a power culture and rules and procedures are minimal; these types of organisations are very political in nature, as decisions are taken upon persuasion rather than on a rational basis (Handy 1993). A role culture is a highly defined structured system where power is purely role based. Subordinates' roles are stratified and their work functions delegated by their supervising authorities- hence the general environment of those organizations are secured and predictable (Handy 1993). According to Handy (1993), organizations that adopt role cultures tend to put their strengths either in their roles and areas of expertise, with very strong hierarchical bureaucracies in place. Hence, power is derived from an individual's organizational position and role and not from expertise or experience. These types of organizations intrinsically are very slow in recognising the need for change, and once these changes are identified are highly resilient towards it. Task culture, is purely 'tasked' or job-oriented where an individual's power is derived from his or her expertise or experienced gained, working in a team setting; as such power results only when needed. Handy (1993) analogises this type of organisational power similar to a 'net' where majority of the power and influence lies at the intersecting parts of the net. A task culture is one that emphasize on 'getting tasks done' and involves a lot organizing and assembling of the suitable resources required, the right type of individuals with suitable ranks in the organisation to ensure that tasks are done and completed on time. This type of culture is characterised as being highly compliant, and applicable to hard workers and middle managers in organizations. A person culture on the other hand is a very interesting mix where individuals tend to believe that they are superior to the organisation they are employed in, for example a law firm with many practising law partners (Handy 1993, p. 90). Within this type of organizational culture individuals can be quite difficult to manage as there is very little influence present to control them. Disciplinary systems and management hierarchies are not practical in these cultures as they are subjected to mutual approval. This culture is highly characteristic to having an expert power-base, where power influence is mutual; individuals are remunerated according to what they are good at and usually there is no loyalty or commitment to the organization they are employed to as they can easily find alternative employment due to their specialisations (Handy1993, p. 191).

Culture is further divided into 'corporate culture' and 'organizational culture'. The main distinction is that corporate culture is a model "devised by management, transmitted, marketed, sold or imposed onto the rest of the organization, with both internal and external image, and action and belief on the rites, rituals, stories and values which are offered to organizational members as part of the seductive processes of achieving membership, acceptance and gaining commitment". 'Organizational culture' on the other hand, connotes to anything that "grows or emerges within the organization that emphasize the creativity of organizational 


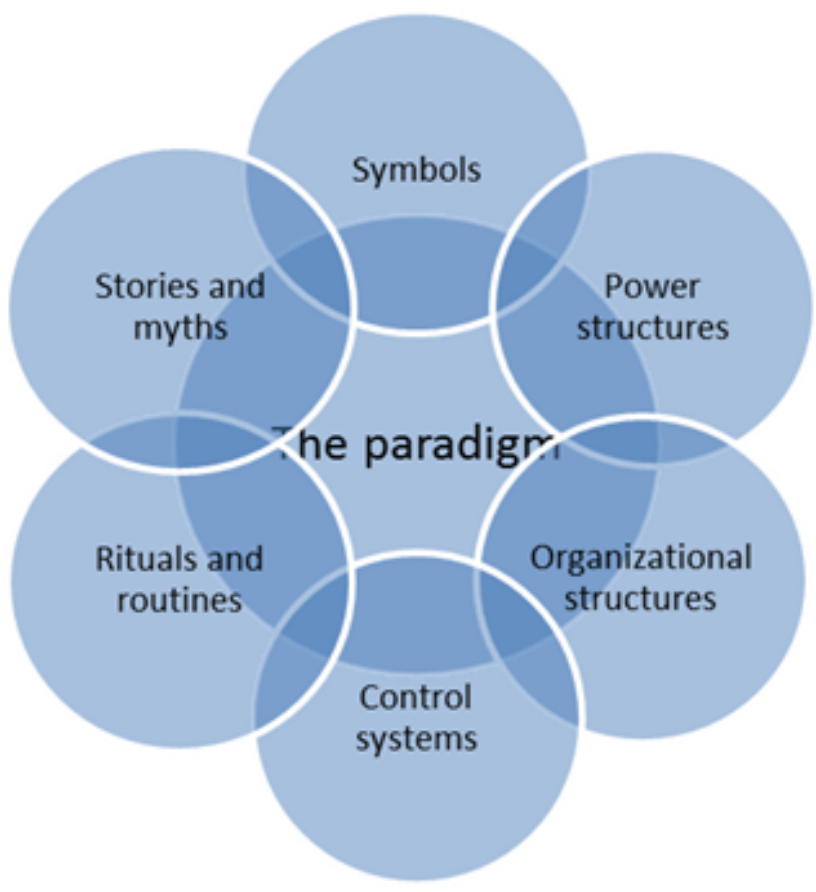

Fig. 1 Culture Web of an Organization

Source: Managing Strategic Change - Strategy, Culture and Action (Johnson, 1991)

members as 'culture-makers', perhaps resisting the dominant culture present". The latter definition highlights the presence of subcultures in organizations, which may be fragmented yet nonetheless existent, but will be the outcome of the cultural processes that take place whenever persons attempt to achieve a collective understanding of the everyday world on order to make it meaningful. Martin (2002) however notes that distinctions should be formulated between the related concepts of organizational culture which are organizational climate, organizational identity and organizational image (Ashkanasy et al. 2000).

Organizational climate or cultural web, pertains to psychological approach to the measurement of content themes (beliefs, values, basic assumptions) or informal practices (behavioural norms), while neglecting the cultural and symbolic forms (stories, physical arrangements, jargon, rituals) that are the core of organizational cultural research. By way of analysis of theme or factors one can see the overall culture of an organization and what works or what needs improving or changed. Yet, given the nature of human beings, it is not possible to significantly change organizations incrementally though the power and influence of those key players as individual mind-set also plays a key factor.

Change may result overtime but this is usually through extreme pressure, which sometimes leads to the extent where individuals would question whether it is feasible talking about changing culture to facilitate strategic change. Johnson (1992) and Anthony (1994) contends that it is the change of behaviours that matters the most as organizations are innately or deeply embedded in a cultural web of stories and myths, rituals and routines, power structures, symbols, control systems, organizational structures which altogether shapes 'the new paradigm' for the organization (see the above in Figure 1). With innovation ecosystems, 
its evolution towards a human-centric innovation ecosystem is the most recent paradigm that encompasses a cross-organizational configuration where the human factor is positioned at the heart of innovation phenomenon. This paradigm incorporates a wide range of inter-organizational cultural networks, organizations and public policy interconnected as the dynamic interactions created are only subjected to time and results. In explaining this framework, innovation posited as intimate, with a close cooperation between the human-factor, its environment and potential technological capabilities. The key and most central feature of this paradigm are the evolving organic, diverse and symbiotic attributes, where the principle of synergy is central, through collaboration, all entities collectively achieve goals that are unattainable on their own. As ecosystems are complex adaptive systems, innovation ecosystems are no more less complex as it encompasses invention/innovation, government, external and internal funding, culture, demand, infrastructural capital and technology that may function virtually or geographically traversing a number of business ecosystems.

\section{Innovation Management and Culture in Organizations}

In focusing on the firm-related factors which potentially affects the innovation process in organizations, a variety of competencies such as coordination and management are required at key stages of the innovation cycle. The elements or areas that should be measured in innovation management includes inputs (people, tools etc.), knowledge management (idea generation), innovation strategy (strategic leadership and orientation), organizational culture (culture and structure), portfolio management (risk/ return balance, optimization of tools etc.) and commercialization (market research and testing, sales, etc.), in order to present the outcome of innovation success or failure at the firm level. In addition, these are the characteristics that influence the innovation process to a further degree in organizations. Undoubtedly, an organization's culture and heritage are considered very important to its technological capabilities in that it helps in nurturing the need to innovate. This is even more emphasized in the extent to which groups and departments are willing to cooperate as problems can arise when individuals are reluctant to collaborate and share ideas. It can affect internal communications, decision-making processes or the pace at which projects are completed as well. However, the difference between an organization's success do not particularly lies in its scientific abilities, rather it is more dependent on its internal ability to collaborate and to share knowledge. This is where culture plays a key role because if the culture of an organization is one that fosters sharing ideas and knowl-

edge then it is likely that firm will have an innovative spirit. Previous experience with innovative projects is highly conducive to an organization's technology and research and development management capabilities, in that it is those skills that are crucial to convert technology into marke products. Many advantages also result from learning to take risks and learning from failure effects. There should also be a commitment to technology and research and development intensity, in that the characteristics of highly innovative firms are those that exhibit patience in allowing ideas to grow and develop overtime. Furthermore, there should be a strong commitment to resource allocation, intellectual input from science, engineering and technology. Absence of this long-term commitment and approach could potentially result in an organizations inability to attract highly skilled talent. Likewise, a non-committal environment, where investments are made one 
then abandoned later on, will most likely alienate persons in which a company encourages creativity, because such a disruptive environment do not foster creativity and will probably cause high labour turnover where employees will endeavour to seek out organizations that are more committed to technology.

Acceptance of risks is another key factor, as it does not pertain willingness to gamble, while on the other hand, it signifies the willingness to consider carefully risky opportunities, the capability to make proper risk assessment decisions, take calculated risks and include them in a balance portfolio of projects where each are evaluated according to a low element of risk and others a high degree of risk. While organizations emphasize on the need for efficiency, there should be some degree of freedom to allow individuals to think, discuss ideas and be creative (Dobini, 2010), although this is not usually widely supported in some specific functional areas. In regards to the best approach to innovation, it is often recommended that a strategic approach be undertaken in that it ensures that an organization can properly develop its plans for the future. This is critical in choosing which markets to compete in or enter and which particular technologies might be well-suited for that organization. It may involve long-term planning and establishing a range of projects that potentially offer new opportunities that can be easily exploited; long-term planning also differentiates these organizations well from their short-term counterparts. Predominantly, organizations usually require a combination of specialists' skills and knowledge to facilitate the cross-fertilisation of the specialist knowledge in order to develop a hybrid environment consisting of individuals that understand a variability of technical subjects to facilitate the transfer of knowledge in a company. Wheelwright and Clarke (1992) contend that 'hybrid managers' that possess technical backgrounds are more likely to be useful in the area of product development. Moreover, the ability to manage the diversity of skills and knowledge in organizations is often what lies at the heart of innovation.

\section{Work Teams and Innovation}

In respect to the strategic nature of work teams and its relationship to organizational performance, one approach would be to view these issues in terms of organizational knowledge. The implication is this case is that recent findings on organizational team working are that the separation of mental and manual labour (qualitative aspects) leads to ignoring key resources such as expertise, expertise, experience and knowledge held by workers which can lead to exploitation. In scientific management and human relations, Taylor (1911) acknowledge that workers possess these qualities however he was worried that it was likely that they would not be exercised to the benefit of the company. With this risk in mind, Taylor (1911) recommends that it is better to formalize and pursue a strategy of close scrutiny and control in organizations. From the total quality management perspective there is a complete reversal from this position in that employees are perceived to be the most knowledgeable and insightful about how they do their jobs, although they do not forthrightly, exercise their insights in the cause of knowledge. Four types of innovation are identified:

- Normal innovation: includes the kind of incremental developments that are part of everyday working and the foundation for more complex innovation 
- Domain innovation: this is a significant development within a specific specialization or subspecialization and requires an expert or a group of experts

- Boundary innovation: this is a significant development that arose from cooperation and coordination across specialisms. This type of innovation requires open-mindedness, dialogue, culture and good working practices to support it

- Radical innovation: is a significant scientific development across disciplines, and to greater extent advancement in knowledge. Bell et al. (1997, p. 59) states that while 'super-scientists' and 'hero-innovators' are involved in this type of innovation, it is important it is diffused and that the organization's general ad overall capacity is greatly increased.

Innovation implies that workers take responsibility or ownership of problems instantaneously, exercise their discretion and participate in problem solving activities while still being necessarily 'policed' by the organization's formal reporting systems. Workers must become more empowered and act on their own initiatives, with their ingenuity skills best captured within a teamwork setting. Mintzberg (1978) however states that the structure of an organization as the sum of the total ways in which it divides the labour into distinct tasks and then achieves coordination among them. In a practical sense, one of the main problems identified when analyzing organizational structure is the recognition that different groups in an organization will behave differently and interact with different parts of the wider external environment. Hence, the tendency will be to label structure at the organizational level with little or no reference or recognition to the differences of groups at the departmental level. However, there have been quite number of research done to establish the link between the link between organizational structure and performance. Burns and Stalker (1961) in an attempt to establish this link through their seminal work on Scottish electronic organizations observed the impact of technical change on organizational structures and the systems of social relationships. From that study it is suggested that 'organic' structures are absent of formality and hierarchy and more inherent to support an innovation culture than do 'mechanistic' structures. While the former is described as being more flexible, adaptable, openly communicative, consensual and less controlled, mechanistic structure offer less than a suitable environment for managing creativity and the innovation process. Regarding organizational formalization and innovation, Burns and Stalker (1961), states that there is an inverse relationship whereby an increase in formalization of procedures results in a decrease in innovation activities, yet it is unclear whether a decrease in procedures and rules would lead to an increase in innovation in an organization. Formalization in organizations is directly linked to centralization as the more decentralized an organization is, the more innovative it will be. This is due to the fact, as there are fewer levels of hierarchy overcome there will be more responsive decision making that is closer to action. However, going back to the principles of scientific management, Taylor (1911) was more interested in revealing workers' knowledge within the context of service to the organization, to highlight that workers usually know more than their managers or superiors. Taylor (1911) contends that systematic soldiering of workers would inherently limit workers and that it would result in controlling instincts would take over any inclination to grant workers the autonomy and discretion to exercise their knowledge freely. In retrospect, this could be the outcome of innovation within an organization context. Therefore, Taylorism is based primarily on the initial gather- 
ing and analysis of workers' knowledge through a 'one-size-fits-all' benchmark to evaluate subsequent work behavior, where any deviation even if it meant improvements in productivity (or continuous improvement), would be seen as a threat to the managerial prerogative to determine work tasks. In regards to continuous improvement processes, Winter (1994) identifies three interdependent elements of this type of relationship. They are corporate knowledge in an organization which is primarily embedded in organizational routines and established through the process of organizational learning. Organizations improve when workers and managers collectively scrutinize existing routines and identify and select new routines, which are derived from examining the likes/dislikes of processes that have evolved from an organization's unique perspective. Moreover, Winter (1994) states that the key and most important element within this process of learning is that elicits and represents the knowledge embedded organizational routines and patterns of work and commonly unearthed through the use of teams. Teams from a long-term aspect, contribute to innovation in organizations. From a contemporary sense, teams convert the move from 'people management' (control) to 'knowledge management' (dissemination). Teams are an important element in ensuring that individual learning within a group setting is transmitted and reflected in organizational activities, and are a source of innovation once a fluid or flexible collective process is achieved (Bell et al. 1997).

When this occurs, work teams should not be coerced into competing with each other and structural arrangement should be put in place in organizations to facilitate cross-functional communications. Work teams

Table 1 Innovation Roles

\begin{tabular}{|l|l|}
\hline Key Individual & Role \\
\hline Technical Innovator & $\begin{array}{l}\text { Expert in one or two fields; generates new ideas and sees new } \\
\text { and different ways of doing them; } \\
\text { Acquires vast amounts of information outside of the organiza- } \\
\text { tion often through networking; } \\
\text { Katekeeper }\end{array}$ \\
$\begin{array}{l}\text { Keeps informed of recent developments that occur outside of the } \\
\text { organization through journals, conferences, other colleagues or } \\
\text { other companies; } \\
\text { Product Champion } \\
\text { Project leader } \\
\text { nization; risk taker; acquires resources and always champions } \\
\text { his or her cause; } \\
\text { Provides the team with leadership and motivation; plans and } \\
\text { organizes the project; ensures that all administrative require- } \\
\text { ments are met and that the project moves forward effectively; } \\
\text { ensures necessary coordination among team members; balances } \\
\text { projects goals with organizational needs; } \\
\text { Usually senior or top management person; provide access to } \\
\text { a power base in an organization; buffers the project team from } \\
\text { necessary organizational constraints; assists the project team to } \\
\text { gets what it needs from other parts of the organization; provides } \\
\text { credibility and organizational confidence in projects. }\end{array}$ \\
\hline
\end{tabular}

Source: Staffing the innovative technology-based organization (Roberts and Fushfield, 1981) 
involved in innovation are crucial for the longevity of organizations as they are important in providing the right amount of support during periods of uncertainty and change, and enable chaos to stimulate creativity

rather than collapse. Through work teams the capacity and ability of employees and staff members can be improved in learning skills, questioning, communicating, modelling, improvising and reconstruction of ideas. 'Virtual teams' to work across sites and disciplines through video conferencing means and intranet technology and 'teamnets' which are clusters of organizations connected through a social network that allows team members to serve customers better than a single company could ensure that the conditions for collaboration are place and interactions are infused among team members (Lipnack and Stamps, 1997). Human factor in the innovation process is consistently acknowledge by scholars, with an emphasis on its particular qualities (Rothwell et al., 1974; Langrish et al., 1972; Utterback, 1975; ven de Ven, 1986; Wolfe, 1994; Martins and Terblanche, 2003).

Rubenstein (1976) states that the innovation process is a 'people process' where successful innovations of the past were as a result of the human factor fulfilling a variety of roles, which in most cases are informal. Table 1 illustrates the key individual roles within the innovation process.

\section{Discussions and Conclusions}

This paper analyzed the role of culture and power on human-centric innovation ecosystems in organizations. When organizations consider implementing innovation the main focus is usually on technology, key capital resources needed for its allocation and how to measure innovation success. Interestingly, organizations tend to pay less attention to other important factors that develop human-centered innovation- which are culture and values (organizational style and approach to innovation), power structures (the overall system of influence relationships between individuals and groups), behavioral approach of teams towards innovation and talent or the human capital which is the creator of innovation. Culture and power play a major role in the development of organizational innovation, especially when internal and external changes potentially threaten its business model. Organizational culture and power are elements that could potentially favor the extent of innovation activities and have the greatest leverage in creating sustainable competitive advantages for organizations, yet it is quite difficult to measure in analyzing the behavior of people in work teams' reception to innovation. Power in one sense enables the shaping of a pro-innovative culture in work teams and individuals which in the long-term forms an organization's competitiveness and position in the market.

On the other hand, the levels, to which innovation is supported, determine the rate at which new nonconventional processes or procedures are implemented. When top management foster support to new ideas from employees (human capital)', innovation thrives well and will be active. The human factor not be confused with human capital is the 'untapped' stock of knowledge, creativity, talents, abilities and skills, training and experience and intelligence, embodied to produce economic value or wealth, and directed to accomplish the goals of a firm or organization. Investing in human capital is one step towards endorsing an organizational culture that supports innovation while shortening the power distance in organizations. This leads to the human capital, in lieu of work groups and individuals to embrace its role and contribution 
in economic development, productivity and growth and an overall justification incorporating a learning environment that leads to innovation development. Brown (1998) highlighted a key point in his definition of culture, in that culture covers a broad spectrum of the behaviors that supports methods of production processes, customs and habits practiced in an organization, which is further supported by Handy who contends that it is the way how things are done around here (Handy, 1976).

Therefore, an organization which has a predominant innovation culture enforced by the power of top management will chiefly operate in a strategic-reflexive mode where innovation results from combining individual interactions $f$ employees and work groups with the common values and goals of the organization. When an organizational culture inherently adopts a culture that is intrinsically built on a system of shared meanings and beliefs where innovation is a natural process and adopted and practiced, innovation will not be viewed as the change for organizational survival rather as the core part of its business model. Innovation is linked intrinsically to entrepreneurship and it is indeed true, as an entrepreneur is the greatest innovator, always adapting to change. From this approach, change or innovation is initiated by an individual's actions and drive to create a business venture of adaptation. Hence the culture will be synonymous to the innovation implemented.

Moreover, for entrepreneur-styled organizations culture could then be perceived as not what an organization has but what it is (Smircich, 1983), and the organization is both a product and a producer of culture. Traditional organizations that adopt the entrepreneurial approach to innovation, will often be the leaders and game changers, adopting a proactive approach to management rather than reactive. Drucker (1985, p. 250) states that innovation is a specific function of entrepreneurship, whether in an existing public or private organization, or new type of business started by a lone individual, where an entrepreneur either creates new wealth-generating resources or utilise existing resources to potentially crate wealth. Given the fact that organizational culture, which derived its roots from sociology and anthropology in the late 1970's, it means that the distinct shared values, norms or belief system practised should guide the attitudes and actions of its members which significantly affects its outcomes. Culture is then affective rather than effective, a used resource to determine an individual's actions, and at the institutional level- used to identify organizations from each other (organizations with superior cultures tend to have a better competitive advantage).

Throughout its history, innovation has been broadly defined as containing certain kind of novelty: artistic, scientific, technological, organizational, cultural, social or individual, has been the premise to many theories and recognized as the key feature of the inventor, scientist, entrepreneur or the firm (Schumpeter, 1934). From the institutional aspect, innovation is recognized as a key characteristic of the individual, as individuals are the creators of innovation. Therefore, in addition to exploring the role of power and culture in human-centric innovation ecosystem, it is necessary as well to analyse the economic aspects of innovation development from two main approaches - the knowledge economy (that is the development of specific ecosystems at the firm and the national levels) and through paradigm shifts, Kuhn's cycle. For the latter, paradigm shifts that chartered the way towards a 'human-centric based innovation ecosystem' came about as a result of due to several economic factors: the political and economic contexts, the industrial and consumer revolutions, the impacts of technologies on individuals and societies, technology as a source of economic growth and 
productivity and the institutionalization of technological invention through patenting and patent laws, and industrial development through R\&D laboratories. From this view innovation, innovation has thus shifted to become more industrially and economically driven due to the new interest in the human factor. The human factor has also been an important and significant part of innovation yet most often ignored. Scholars predict that investing in the human capital to harness more skills based-on-the job-training and education can foster and transform economies into high innovators. In terms of global economics, the genesis of innovation derives from a wide range of sources. Innovation development does involve various stages, considerable investment, non-linear progression, and constant feedback of vital information in the whole process. The latter part of the last century demonstrates that many models' guidelines and tools have been developed to assist organizations in gaining success in innovation. It is even argued that by following a formalised model organization are able to improve its level of product development in innovation (Engwall et al., 2005), however scientific evidence is still unclear as to the extent to which organizations' and managers' practical actions actually adhere to the formalised model. Human-centric innovation ecosystems are highly dependent on those models that create 'its legitimacy' through support, management control and commitment from work teams (Sapolsky, 1972; Brunsson, 1980; Huczynski, 1993; Hodgson, 2002). The entrepreneurial model, which purely recognises human factor to be the centre and the heart of innovation ecosystems, is also widely accepted as the key factor in organizational innovation as well. It is 'role of the entrepreneur' or human factor that is often missing in many models of innovation. Even in thriving, profitable organization who have for many years achieved innovation success, top managers have to be constantly reminded of the responsibility to acknowledge and support 'innovation leaders' which in simple terms is the human factor or people who through exercising their initiative and the willingness to take on risks, ultimately creates innovation. Hence, the entrepreneurial model is more likely to create an innovation culture in organisations, where greater visibility of the role of the human factor is emphasized and supported as the creator of innovation in innovation ecosystems.

\section{References}

Ashkanasy, N. M., Wilderom, C. P. M. and Peterson, M. F. (2000). Handbook of Organizational Culture and Climate. Thousand Oaks, CA, Sage.

Bell, L., Blacker, F. and Crump, N. (1997). "Look Smart." People Management, Vol. 23 (October), pp. 5659.

Brown, A. (1998). Organizational Culture (2nd Edition). London: Financial Times/Pitman.

Brunsson, N. (1980). "The functions of project management." The Journal of Management Studies, Vol. 10, Issue 2, pp. 61-7.

Burns, T. and Stalker, G. M. (1961). The Management of Innovation. London, Tavistock.

Dobini, C. (2010). "The Relationship between an Innovation Orientation and Competitive Strategy." International Journal of Innovation Management, Vol. 14, Issue 2, pp. 331-357.

Drennan, D. (1992). Transforming Company Culture. London, McGraw-Hill.

Drucker, P. F. (1985). Innovation and Entrepreneurship, p. 250. UK, HarperCollins Publishers Ltd. 
Engwall, M., Kling, R. and Werr, A. (2005). "Models in Action: How Management Models are Interpreted in New Product Development." R\&D Management, Vol. 35, Issue 4, pp. 427-439.

French, J. R. P., and Raven, B. (1959). "The Bases of Social Power." In Cartwright, L. and Zander, A. (eds), Group Dynamics, Research and Theory. London, Tavistock.

Godin, B. (2008). "Innovation: The History of a Category." Project on the Intellectual History of Innovation, Working Paper No. 1.

Handy, C. B. (1976). Understanding Organizations. UK, Oxford University Press.

Handy, C. B. (1993). Understanding Organizations (3rd edition). Harmondsworth, Penguin Harvard Law School's Berkman Center for Internet and Society. United States.

Hodgson, D. (2002). "Disciplining the Professional: The Case of Project Management." The Journal of Management Studies, Vol. 39, Issue 6, p. 803.

Huczynski, A. (1993). Management Gurus. London, Routledge.

Jacques, E. (1952). The Changing Culture of a Factory. New York, Dryden Press.

Johnson, G. (1991). "Managing Strategic Change - Strategy, Culture and Action." Long Range Planning 25, p. 34 .

Johnson, G. (1992). "Managing Strategic Change - Strategy, Culture and Action." Long Range Planning 25, Issue 1, pp. 28-36.

Kotter, J. (1977). "Power, Dependence and Effective Management." Harvard Business Review, Vol. 55, Issue 4, pp. 125-136.

Kuhlmann, S. (2001). "Future Governance of Innovation Policy in Europe - Three Scenarios." Research Policy, Vol. 30, pp. 953-976.

Kuhn, T. (1970). The Structure of Scientific Revolutions (2nd, enlarged ed.). United States, University of Chicago Press.

Langrish, J., Gibbons, M., Evans, W. G. and Jevons, F. R. (1972). Wealth from Knowledge. London, Macmillan.

Lipnack, J. and Stamps, J. (1994). The Age of the Network: Organizing Principles for the 21st Century. New York, John Wiley \& Sons Inc.

Lorsch, J. (1986). "Managing Culture: The Invisible Barrier to Strategic Change." California Management Review, Vol. 28, Issue 2, pp. 95-109.

Marcum, J. A. (2005). Thomas Kuhn's Revolution: An Historical Philosophy of Science. Continuum 2005.

Martin, J. (2002). Organizational Culture: Mapping the Terrain. Thousand Oaks, CA, Sage.

Martins, E. C. and Terblanche, F. (2003). "Building Organizational Culture that Stimulates Creativity and Innovation." European Journal of Innovation Management, Vol. 6, Issue 1, pp. 64-74.

Mintzberg, H. (1978). "Patterns in Strategy Formulation." Management Science, Vol. 24, pp. 934-948.

Mintzberg, H. (1983). Power in and Around Organizations. Englewood Cliffs, NJ, Prentice Hall.

Nowotny, H. (2008). "Insatiable Curiosity: Innovation in a Fragile Future." Cambridge (Mass.): MIT Press.

Nowotny, H. (2006) The Quest for Innovation and Cultures of Technology, in H. Nowotny (ed.), Cultures of Technology and the Quest for Innovation (pp. 1-38). New York: Berghan Books. 
Pacanowsky, M. E., and O'Donnell-Trujillo, N. (1982). "Communication and Organizational Culture." The Western Journal of Speech and Communication, Vol. 46 (spring), pp. 115-130.

Roberts, E. B. and Fushfield, A. R., (1981). "Staffing the Innovative Technology-based Organization." Sloan Management Review, Spring, pp. 19-34.

Rothwell, R., Freeman, C., Horlsey, A., Jervis, V. T. P., Robertson, A. B. and Townsend, J. (1974). "SAPPHO Updated: Project SAPPHO phase II." Research Policy, Vol. 3, pp. 258-291.

Rowley, J. (2001). "Knowledge Management in Pursuit of Learning: the Learning with Knowledge Cycle." Journal of Innovation Science, Vol. 27, Issue 4, pp. 227-237.

Rubenstein, A. H. (1976). "Factors Influencing Success at the Project Level." Research Management, Vol. 19, Issue 3, pp. 15-20.

Sapolsky, H. (1972). The Polaris System Development. Harvard University Press, MA, Cambridge.

Schein, E. (1985). Organizational Culture and Leadership. San Francisco, CA, Jossey-Bass.

Schumpeter, J. (1934). The Theory of Economic Development. New Brunswick, Transaction Publishers.

Simonen, J. and McCann, P. (2008). "Firm Innovation: The Influence of R\&D Cooperation and the Geography of Human Capital Inputs." Journal of Urban Economics, Vol. 64, Issue 1, pp. 146-154.

Smircich, L. and Morgan, G. (1982). "Leadership: The Management of Meaning." Journal of Applied Behavioural Science, Vol. 18, Issue 2, pp. 257-273.

Storper, M. and Scott, A. J. (2009). "Rethinking Human Capital, Creativity and Urban Growth." Journal of Economic Geography, Vol. 9, Issue 2, pp. 147-167.

Taylor, F. W. (1911). The Principles of Scientific Management. New York, NY, USA and London, UK, Harper \& Brothers.

The Economics of the arts, edited by Mark Blaug (1976). Gregg Revivals; First Edition (December 1992).

Utterback, J. M. (1975). "The Process of Technological Innovation within the Firm." Academy of Managent Review, Vol. 12, pp. $75-88$.

Wheelwright, S. C. and Clark, K. B. (1992). Revolutionising Product Development. New York, The Free Press.

Winter, S. G. and Nelson, R. R. (1982). An Evolution Theory of Economic Change. Harvard University Press, MA, Cambridge.

Wolfe, R. A. (1994). "Organizational Innovation: Review and Critique and Suggested Research Directions." Journal of Management Studies, Vol. 31, Issue 3, pp. 405-431. 